\title{
Methods of Dealing with Frost Heaving of Seasonally Freezing Soils in the Foundations of Buildings and Structures
}

\author{
Andrey KRAEV ${ }^{1}$, Aleksey KRAEV ${ }^{1}$, Dmitriy SKVORTSOV ${ }^{1}$, Mikhail DERYABIN ${ }^{1}$ \\ ${ }^{1}$ Tyumen Industrial University, Tyumen, Russian Federation
}

\begin{abstract}
In the article, the authors consider the problem of building shallow foundations on seasonally freezing heaving soils associated with uneven deformations of the soil base and the cost of construction when laying the foundations of buildings and structures below the freezing depth. The authors systematized information on existing methods of dealing with frosty heaving of seasonally freezing soils in the foundations of buildings and structures, including: thermal reclamation of soils, hydromelioration, physical and chemical measures, construction and structural measures and reinforcement with geosynthetic materials (as a special case of construction and construction measures). The building materials used are described with an indication of their characteristics. The results of experimental studies of scientists using these methods are presented. Schemes and drawings of the considered methods of dealing with frost heaving of soils are given. The advantages and disadvantages of the considered methods of combating frost heaving of the soil are reflected. Studies of the use of geosynthetic materials in both thawed and frozen soils are reflected. The results of experimental laboratory studies carried out by the authors of the article on the effectiveness of the contour reinforced along the contour of a sand cushion located at the base of seasonally freezing heaving soils are presented. The main conclusions on the considered methods of combating frost heaving of soils are formulated.
\end{abstract}

Key words: seasonally freezing soils, frost heaving deformations, heaving soil, frost heaving, thermal reclamation, hydromelioration, soil salinization, soil hydrophobization, reverse slope foundations, TISE anchor piles, sand cushion, soil replacement, geosynthetics, experimental studies, shallow.

\section{INTRODUCTION}

The construction of shallow foundations on seasonally freezing soils is accompanied by certain difficulties due to uneven deformations of the soil base caused by frost heaving, and deepening the foundations below the depth of soil freezing leads to a significant increase in the cost of the foundation.

As construction practice shows, the location of shallow foundations below the freezing depth and, even the construction of deep foundations (pile), on heaving soils is not always advisable, namely, for buildings and structures with insufficient load on the base. This pattern was noted by V.P. Marakhtanov [1], V.V. Pazinyak [2]. In this regard, the determination of the optimal ways to reduce the influence of heaving of soils on the structures of buildings and structures becomes an urgent task.

\section{MATERIALS AND METHODS}

At the moment, the existing methods for reducing the heaving of soils can be conditionally divided into the following methods:

1. thermal melioration;

2. hydro reclamation;

3. physical and chemical measures;

4. construction and structural measures;

5. reinforcement with geosynthetic materials (a special case of construction and structural measures).

1. Thermal reclamation - measures aimed at preventing or reducing deformations of frost heaving by regulating the temperature regime of the subgrade.

One of these methods is the device of local thermal insulation of the soils of the foundations. The following materials are used as heat-insulating materials:

- styrofoam $(\lambda=0.037-0.049 \mathrm{~W} / \mathrm{m} * \mathrm{C})$;

- extruded polystyrene foam $(\lambda=0.029-0.030 \mathrm{~W} / \mathrm{m} * \mathrm{C})$;

- glass and stone wool $(\lambda=0.030-0.053 \mathrm{~W} / \mathrm{m} * \mathrm{C})$;

- polyurethane foam $(\lambda=0.020-0.041 \mathrm{~W} / \mathrm{m} * \mathrm{C})$;

- penoizol $(\lambda=0.047 \mathrm{~W} / \mathrm{m} * \mathrm{C})$;

- expanded clay $(\lambda=0.070-0.016 \mathrm{~W} / \mathrm{m} * \mathrm{C})$;

- perlite sand $(\lambda=0.040-0.060 \mathrm{~W} / \mathrm{m} * \mathrm{C})$;

- foam glass $(\lambda=0.040-0.080 \mathrm{~W} / \mathrm{m} * \mathrm{C})$;

- coarse-grained expanded clay concrete and foam concrete $(\lambda$ $=0.011-0.029 \mathrm{~W} / \mathrm{m} * \mathrm{C}$ ).

The effectiveness of the method consists in reducing the freezing of the soil base, and, as a consequence, reducing the volumetric ice content of the soil. Research in this direction is reflected in the works of A.V. Melnikova [3], A.A. Dorofeeva [4], I.V. Shestakova [5], S.V. Chetkareva [6], E.E. Nukhova [7]. The admissibility of the use of thermal insulation for shallow-deep foundations on heaving soils is described in STO 36554501-012-2008 NIIOSP, where polystyrene foam extrusion plates are considered as a heater material (Figure 1). 


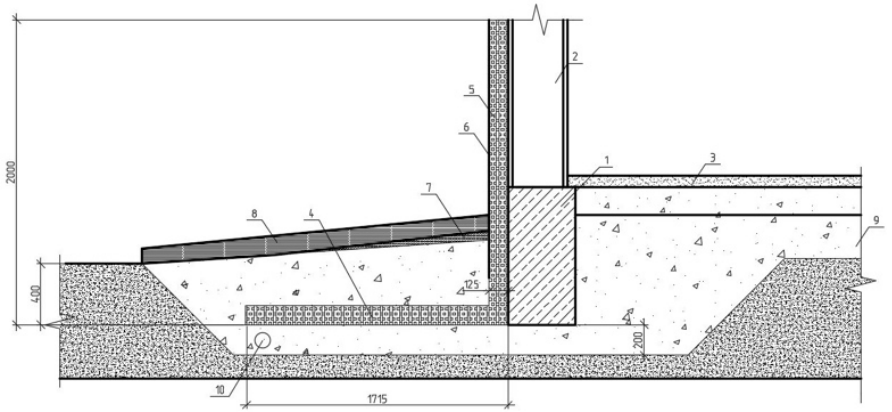

Figure 1: Layout of thermal insulation in the foundations of heated buildings without floor thermal insulation according to STO 36554501-012-2008 (compiled by the authors).

In the diagram: 1 - foundation; 2 - building wall; 3 - floor of the building; 4 - horizontal thermal insulation; 5 - vertical thermal insulation; 6 - protective coating; 7 - sand preparation for the blind area; 8 - asphalt or concrete blind area; 9 - non-porous soil; 10 - drainage; $\mathrm{L}_{\mathrm{c}}, \mathrm{D}_{\mathrm{h}}, \delta_{\mathrm{h}}$ - overall dimensions of the heatinsulating skirt.

The advantage of this method is a decrease in the depth of laying the foundations with a concomitant reduction in the cost and labor costs for the construction of the zero cycle of construction by reducing the volume of earthworks to excavate the pit.This group of measures also includes the use of heating installations, laying along the contour of the foundations of an electric heating system, engineering networks and communications that emit heat that prevents soil freezing. However, these measures lead to a significant rise in the cost of construction and an increase in operating costs.

2. Hydro reclamation - measures aimed at preventing or reducing deformations of frost heaving, by reducing the moisture content of the freezing base of the foundation. The effectiveness of the method lies in reducing the ice content of the frozen soil massif, and, as a consequence, reducing frost heaving.

The most common measure is the installation of drainage systems for the removal of surface and groundwater. One of the authors who studied this method is A.I. Yarmolinsky, who proposed a "soft drain" type drainage filter made of non-woven needle-punched geotextile material, folded in a certain way and arranged in a soil base [8]. This method has proven itself well, however, the work on its implementation is quite laborious and expensive, therefore this method has not become widespread in construction. The use of drainages in the design of buildings and structures is reflected in sufficient detail and justified by calculations in RMD 50-06-2009 (Figure 2).

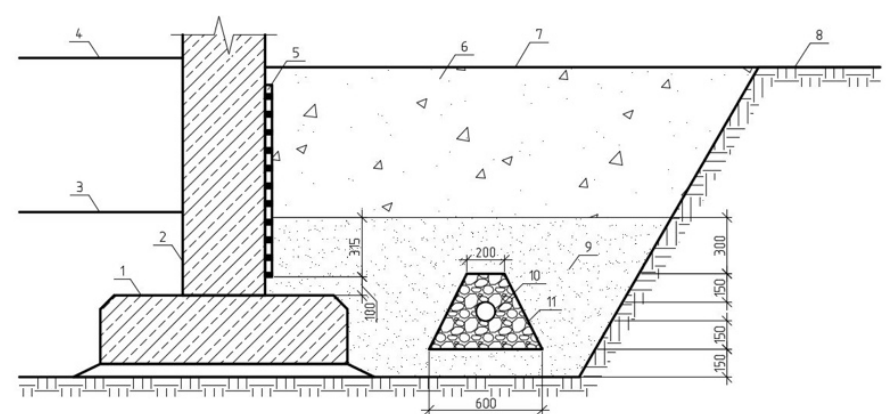

Figure 2:Drainage scheme with insulating geocomposite according to RMD 50-06-2009 (compiled by the authors).
In the diagram: 1 - foundation; 2 - building wall; 3 - basement floor of the building; 4 - clean floor of the 1st floor of the building; 5 - geocomposite; 6 - backfilling; 7 - design surface; 8 - existing surface; 9 - sand with $\mathrm{k}_{\mathrm{f}} \geq 5 \mathrm{~m} / \mathrm{s} ; 10$ - drainage pipe; 11 - Crushed stone M1000-1200, fraction 3-10 mm.

3. Physical and chemical measures - measures aimed at preventing or reducing deformations of frost heaving by changing the physical and chemical composition of soils. The main methods of these measures are: impregnation of soils with sodium hydroxide solution with the addition of quicklime, salinization of soils, hydrophobization of soils with a binding material under certain hydrothermal conditions.

Research by A.B. Samoilenko and V.N. Shestakov [9] showed that soil impregnation with sodium hydroxide solution with addition of quicklime can reduce the relative deformation of frost heaving of the soil up to three times.

The effectiveness of soil salinization consists in reducing the freezing temperature of soil moisture, and, as a consequence, in reducing the volumetric ice content of soils, which in turn reduces their heaving.

The question of the effectiveness of hydrophobization (imparting water-repellent properties to the soil) was studied by I.N. Khabbibulin and M.E. Beshenov [10]. Usually used as a binder: resins, petroleum bitumens, wood, peat and liquid coal tar.

These methods are quite complex in the device, and besides, they have a number of serious drawbacks, which prevents their widespread distribution:

- an increase in the thermal diffusivity of the soil;

- increasing the aggressiveness of the $\mathrm{pH}$ of the environment for structures;

- short-term action (up to 5-7 years);

- the possibility of increasing the heaving of the soil, after desalination (for hydrophobization of soils);

- high toxicity and flammability (for hydrophobization of soils);

- the complexity and need for processing and disposal of soil after the termination of the additives.

The listed disadvantages impose restrictions on the use of these measures to improve the properties of the foundations of buildings and structures of capital construction, however, they do not prevent the use of physical and chemical measures to improve the properties of the foundations of auxiliary temporary household structures in seasonally freezing heaving soils.

4. Construction and structural measures - measures aimed at preventing or reducing deformations of frost heaving by arranging various structural measures aimed at changing the operation of the base-foundation-structure system.

A fairly large number of construction and structural measures were proposed back in the XX century, most of which are reflected in the guidelines for the design of foundations and foundations on heaving soils developed by the N.I. Gersevanov in 1979, namely: anchoring of foundations and structures, arrangement of rigid movable shells around foundations, reduction of the cross-sectional area and an increase in the load on the foundations, arrangement of inclined side edges of foundations, installation of coatings and films on the side surfaces of foundations. The listed methods worked well, but 
they were not universal and did not solve the problem of construction on heaving soils everywhere, which led to the need to develop new measures. Some of these activities are shown in Figure 3.
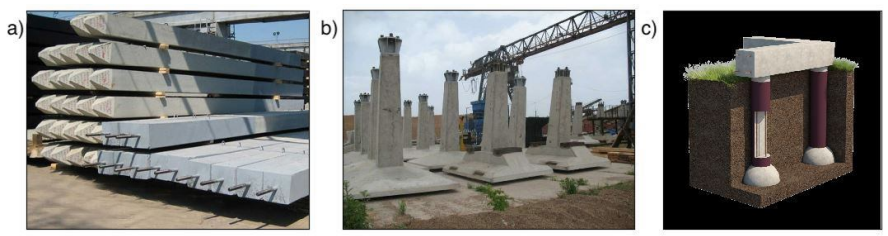

Figure 3:Construction and construction measures: a) piles covered with organosilicon enamel; b) foundations with a reverse slope and anchors; c) anchor piles according to the technology of individual construction and ecology (TISE) (compiled by the authors).

Replacing heaving soil with non-heaving soil. This method makes it possible to significantly reduce the deformations of frost heaving of the soil base, leaving them in acceptable values or completely exclude them when replacing the soil for the entire thickness of the freezing layer. As a replacement, they use: sandy soils of large and medium size [11], crushed stone, gravel, slag [12], asbestos ballast [13], foam glass crushed stone [14]. The disadvantage of this method is a rather large amount of zero cycle work.

Increasing the strength properties of soils with cement mortars. Research in this direction was carried out by N.M. Krasinikova, O.V. Khokhryakov and V.G. Khozin, who established as a result of laboratory experiments that the use of CNV (cement of low water demand, $16 \%$ of the mass of soil with a CNV-30 content of $4.8 \%$ ) can reduce frost heaving deformations from an excessively heaving to a non-heaving state [15]. The disadvantage of this measure is a significant increase in the cost of work due to the cementation of soils under pressure, and, therefore, the use of a specialized technique for injecting a high-pressure solution.Installation of piles of foundations with a reverse slope and variable cross-section. O.V. Tretyakov and B.S. Yushkov developed and propose to use these measures for the perception of frost heaving forces and reducing deformations due to the static potential of the pile. Within the inclined surface, there is a vertical component of frost heaving forces directed downward from the day surface, partially compensating for the tangential forces $[16,17]$. The scheme of using anchor piles of variable cross-section in the structure of a retaining wall is shown in Figure 4.
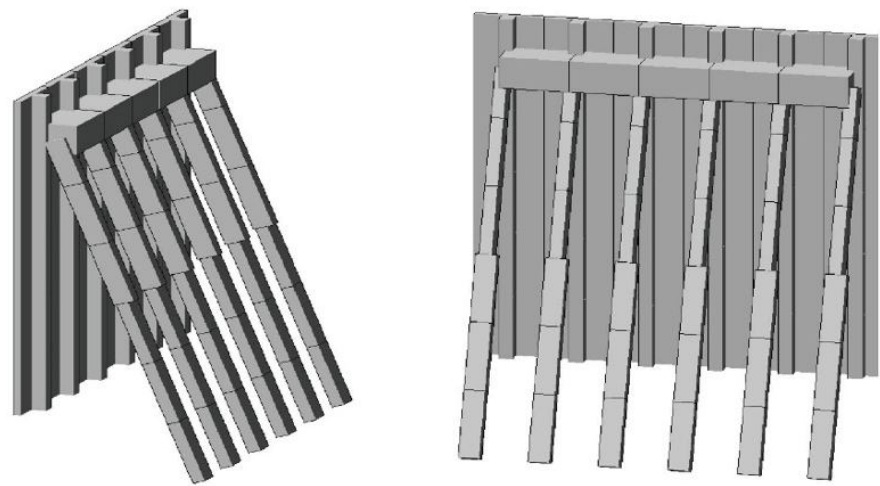

Figure 4: Anchor piles of variable cross-section in the structure of retaining walls [17].
Installation of screw and screw conical-spiral piles.V.I. Aksenov et al. Determined the efficiency and possibility of using screw piles in frozen soils.

I.V.Noskov and A.V.Sviredskikh, during a series of laboratory and field experiments, found that the use of helical cone-spiral piles (HCSP) with a small area of contact between the pile and the ground does not allow the pile to move even when it is deeply frozen. The authors believe that the reason for a significant decrease in the deformations of frost heaving of soils is soil compaction in the intervals between branches and the squeezing of groundwater [18]. The general view of these piles is shown in Figure 5.

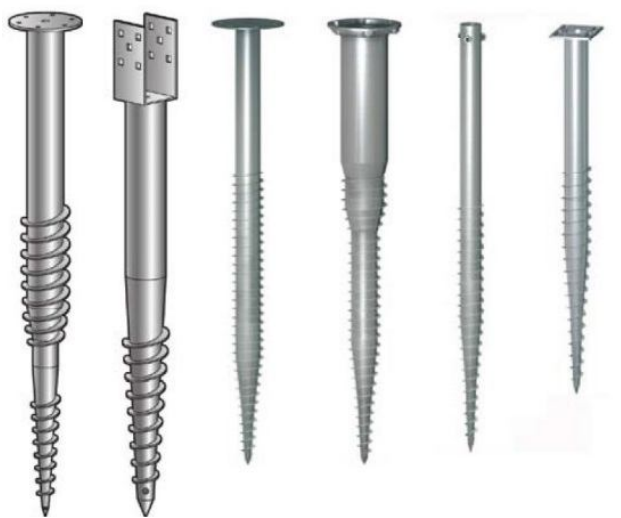

Figure 5:Helical cone-spiral piles (HCSP) [18].

One of the new directions of this group of activities is the reinforcement of foundations with geosynthetic materials, the research of which in frozen soils is currently devoted to a small number of works.

5. Reinforcement with geosynthetic materials - measures aimed at preventing or reducing deformations of frost heaving, by installing reinforcing elements with high tensile strength in the soil base. These measures are one of the effective methods for improving the properties of soils [19] and belong to the construction-structural group.

At present, synthetic materials (geosynthetics) are a rapidly developing family of materials. The main types of which are: geotextiles, geogrids, geomembranes, geocomposites. The listed geosynthetic materials are shown in Figure 6.

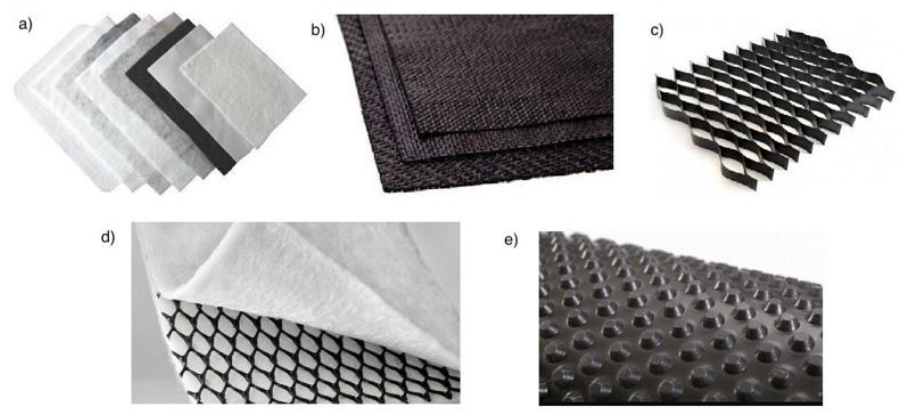

Figure 6: Modern geosynthetic materials: a) geotextiles; b) woven geotextile; c) geogrid; d) geocomposite; e) geomembrane. (compiled by the authors).

A fairly large number of works by the authors are devoted to the study of the applicability of geosynthetic materials in thawed soils: I.T. Mirsayapov and R.A. Sharafutdinov [20]; 
YES. Tatyannikov and A.B. Ponomarev [21]; B.S. Yushkov and O.A. Sannikov [22]; An.N. Kraev [23, 24]; Yu.A. Novikov [25]; A.S. Grishina, A.V. Mashchenko, A.B. Ponomarev [26], A.S. Kuznetsova, V.G. Ofrichter [27]. The authors found that the use of reinforcing materials allows several times to increase the bearing capacity of the soil base, depending on the location and number of reinforcing elements.

Much less research has been devoted to the applicability of geosynthetics in frozen soils. A.V. Mashchenko and A.B. Ponomarev established the inadmissibility of using fiber reinforcement of clay soils due to a significant (up to 2 times) increase in frost heaving deformations [28]. I.A. Chernyshev and A.V. Mashchenko determined that the reinforcement of heaving soils with woven geotextiles and geocomposite can reduce the deformations of frost heaving of soils by up to $25 \%$ [29]. S.I. Sushkov and A.S. Sergeev, based on the results of laboratory experiments, it was found that the use of geosynthetic lattice and geotextile material in the construction of pavement reduces the accumulation of moisture and water saturation of clay soil at the junction with sand, which leads to a decrease in frost heaving of soils [30].

The authors proposed and carried out an experimental study in laboratory conditions of a sandy reinforced along the contour of a pillow in seasonally freezing clay soils. According to the results of the experiments, it was found that the use of contour reinforcement allows to reduce the deformation of frost heaving by $10 \%$ and excludes the process of freezing of clay soil with sand, reduces the shrinkage of the subgrade during the initial period of freezing by $24 \%$ and subsidence of the soil after thawing by $29 \%$. compared to a sandy pillow without reinforcement $[31,32,33]$. The general view of the experimental setup is shown in Figure 7.

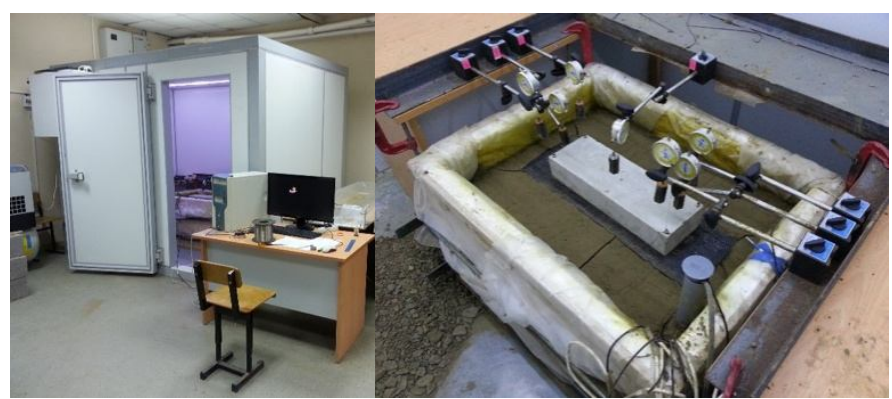

Figure 7: General view of the experimental setup placed in a freezer (compiled by the authors).

\section{RESULTS}

Studies of structures made of reinforced soil by the above authors and the experience of their application have shown a number of advantages compared to traditional structures and materials: the possibility of using local soil as the main building material, the possibility of construction in any conditions, low cost with the speed and ease of construction, reducing the cost of the device works of the zero cycle of construction.

\section{CONCLUSION}

Summarizing the above, the following conclusions can be drawn:

1. At the moment, there are no universal measures aimed at preventing or reducing the effect of frost heaving forces on the structures of the foundations of buildings and structures.

2. Hydromechanical reclamation and cementation of soils are effective methods that make it possible to almost completely eliminate frost heaving of soils, but they are quite expensive compared to other measures, as a result of which they have not been widely used at the moment.

3. Physicochemical measures are complex in production and have a large number of shortcomings in the arrangement of the foundations of the foundations of buildings and structures for capital construction, however, these shortcomings are not critical for the arrangement of the foundations of the foundations of temporary utility structures.

4. In terms of a combination of factors, thermal reclamation and construction and construction activities are most widespread at the moment.

5. The use of geosynthetic reinforcing materials to improve the properties of seasonally freezing soils is a promising area that requires further study.

\section{REFERENCES}

[1] V.P. Marakhtanov."Cryogenic deformations of the pile foundation of pipelines", Pipeline transport: theory and practice, No. 5 (39),pp. 18-22, 2013.

[2] V.V. Pazinyak, N.B. Kutvitskaya and M.A. Minkin"Experimental studies of the stability of pipelines on a large-scale soil model",Cryosphere of the Earth, vol. X. iss. 1,pp. 51-55, 2006.

[3] A.V. Melnikov."Influence of thermal insulation of foundations on the change in the temperature regime of a seasonally freezing base in an area of deep seasonal freezing", Bulletin of civil engineers, No. 6 (35), pp. 77-83, 2012.

[4] A.A. Dorofeev and V.A. Krutikov."Influence of the use of heat-insulating materials on the heaving properties of soil foundations of roads", Technical regulation in transport construction, No. 2 (16), pp. 51-56,2016.

[5] I.V. Shestakov. "Investigation of the temperature regime of heaving soils in the southern regions of the Far East",Fundamental research, No. 11-2, pp. 328-332.2016.

[6] S.V. Chetkareva, E.E. Nukhova, I.N. Chernyshov, V.A. Krutikov, T.M. Mikhalkina, G.I. Yakovlev. "Method of protecting the foundation from frosty heaving of peat soil using penoplex", Young scientists - accelerating scientific and technological progress in the XXI century, pp. 830-834,2015.

[7] E.E. Nukhova, I.N. Chernyshov, S.V. Chetkarev, V.A. Krutikov, T.M. Mikhalkina, G.I. Yakovlev.'The effectiveness of using expanded clay as a heat-insulating material in the construction of a foundation on a clay base", Young scientists - accelerating scientific and technological progress in the XXI century, pp. 964-969,2015.

[8] A.I. Yarmolinsky, V.V. Lopashuk, A.V. Lopashuk, V.S. Svetenok. "Using geosynthetic materials to improve the 
water-thermal regime of highways", Far East. Highways and traffic safety, pp. 87-92,2013.

[9] A.B. Samoilenko, V.N. Shestakov."Influence of sodium hydroxide solution on frost heaving of clay soil",Bulletin of the South Ural State University. Seria: construction and architecture, No. 33 (209),pp. 29-31,2010.

[10] I.N. Khabibulina, M.E. Beshenov, T.I. Geleverya."The use of fortified soils for the device of anti-heap layers on highways", IzvestiaKazGASU, No. 2(16), pp. 257-261,2011.

[11] V.D. Karlov.Seasonally freezing soils as foundations of structures: dis. for a job. uch. step. dr. tech. Sciences (05.23.02); SPbGASU. - St. Petersburg, 349 p,1998.

[12] V.A. Shorin, G.L. Kagan, A. Yu. Velsovsky."Scientific developments in the field of construction of structures on seasonally freezing soils", Bulletin of the Vologda State University. Series: technical sciences, No. 1 (1), pp.94-99, 2018.

[13] G.K. Shchepotin, M.A. Mashkin."Increasing frost resistance of the roadbed-on highways", News of higher educational institutions. Construction, No. 3, pp. 85-91,2015.

[14] G.V. Mosolov, V.A. Kumallagov."Experimental use of foam glass crushed stone in the construction of trunk pipeline facilities in difficult geocrylogic conditions", Science and technology of pipeline transport and oil products, No. 2 (9), pp. 174-180,2019.

[15] N.M. Krasinikova, O. V. Khokhryakov, V.G. Khozin. "Influence of cements of low water demand on the degree of heaving of dusty soils", Izvestia KGASU, No. 3(21), pp. 139-143,2012.

[16] O.V. Tretyakova."Piles with a reverse slope of the surface for transport structures in seasonally freezing soils", Innovative factors of transport development. Theory and practice. Materials of the international scientific and practical conference. - Novosibirsk. pp. 207-214,2017.

[17] O.V. Tretyakov, B.S. Yushkov."Optimization of the shape of piles of thin retaining walls", Materials of the conference. Ecology and scientific and technological progress. Urban studies. - Perm. pp. 522-533,2015.

[18] I.V. Noskov, A.V. Sviderskikh."Work of screw-conicalspiral piles in conditions of frost heaving of soils", Bulletin of civil engineers, No. 1 (72), pp. 67-75, 2019.

[19] A.S. Grishina, A.V. Mashchenko, A.B. Ponomarev."Results of studies of the strength characteristics of clayey soils reinforced with various geosynthetic materials", Bulletin of the Perm National Research Polytechnic University. Applied ecology. Urban studies,No 4, pp. 9-21, 2015.

DOI 10.15593 / 240935125 / 2015.04.01.

[20] I.T. Mirsayapov, R.A. Sharafutdinov."Bearing capacity and sediments of a soil base reinforced with vertical and horizontal elements". Engineering and geotechnical surveys, design and construction of foundations, foundations and underground structures. Proceedings of the All-Russian Scientific and Technical Conference. - SPb. pp. 169-174,2017. [21] D.A. Tatyannikova, A.B. Ponomarev."Model stamping tests on the study of the work of reinforced foundation pads under load", Engineering and geotechnical surveys, design and construction of foundations, foundations and underground structures. Proceedings of the All-Russian Scientific and Technical Conference. -SPb, pp. 219-223, 2017.
[22] B.S. Yushkov, O.A. Sannikova."Device and development of a roadbed structure on soft soils", Transport structures, No. 4 (4), pp. 1-8, 2014.

[23] A.N.Kraev, V.F. Bai."Study of the work of a sandy reinforced pillow with a curvilinear sole in conditions of weak soils", Bulletin of civil engineers, No. 3, pp. 107-110, 2014

[24] A.N.Kraev."Experimental studies of the work of a weak clay base reinforced with a sandy reinforced pad with a curved base", Scientific and technical bulletin of the Volga region, No. 5, pp. 221-224, 2013.

[25] Yu.A. Novikov. Study of the operation of sandy contour-reinforced piles in weak clay bases under strip foundations: dis. for a job. uch. step. Cand. tech. Sciences (05.23.02); TyumGASU. - Tyumen, 140 p, 2015.

[26] A.S. Grishina, A.V. Mashchenko, A.B. Ponomarev."Results of studies of the strength characteristics of clayey soils reinforced with various geosynthetic materials", Bulletin of PNRPU. Applied ecology. Urban studies, No. 4, pp. 9-21, 2015.

[27] A.S. Kuznetsova."Evaluation of the strength of fiberreinforced sand based on the results of triaxial compression tests”. Vestnik PNRPU. Geotechnics, No. 2,pp. 37-44, 2012.

[28] A.V. Mashchenko, A.B. Ponomarev."Analysis of the Influence of Fiber-Fiber Reinforcement on the Properties of Clay Soils in Conditions of Seasonal Freezing and Thawing”, Bulletin of the Volgograd State University of Architecture and Civil Engineering. Series: Building and architecture, No. 44-1 (63), pp. 40-50, 2016.

[29] I.A. Chernysheva, A.V. Mashchenko."Comparison of methods of protection against frost heaving of soil", Bulletin of PNRPU. Construction and architecture, Volume 4, No. 4,pp. 64-72, 2016.

[30] S.I. Sushkov, A.S. Sergeev."Experimental comparison of two designs of road pavements using geogrids arranged on the slopes of forest roads, at the base of which there is water-saturated clay soil", Forestry journal, No. 1, pp. 126136, 2017.

[31] D.S. Skvortsov, An.N. Kraev, Al.N. Kraev, P.I. Vasenin."Experimental studies of a sand cushion with contour reinforcement in seasonally freezing heapy soils", Bulletin of civil engineers, No. 5 (64), pp. 98-102, 2017.

[32] O.T.Cherney, Z.V.Smirnova, O.I. Vaganova andV.A. Razorenov."Strengthening technologies of different types of foundations in buildings". International Journal of Emerging Trends in Engineering Research, 8(6), pp. 23382341, 2020. doi:10.30534/ijeter/2020/22862020.

[33] M.A.Saaideh, O.Ananbeh, T.Almomani, E.A.Feilatand H.J.Khasawneh. "Power quality audit of a school of engineering building - case study". International Journal of Emerging Trends in Engineering Research, 8(1), pp. 151-156, 2020. doi:10.30534/ijeter/2020/20812020 